\title{
Cell Shape and Cardiosphere Differentiation: A Revelation by Proteomic Profiling
}

\author{
Nanako Kawaguchi, ${ }^{1}$ Mitsuyo Machida, ${ }^{2}$ Kota Hatta, ${ }^{3}$ \\ Toshio Nakanishi, ${ }^{1}$ and Yohtaroh Takagaki ${ }^{1,4}$ \\ ${ }^{1}$ Department of Pediatric Cardiology, Tokyo Women's Medical University, 8-2, Kawada-cho, Shinjuku, \\ Tokyo 162-8666, Japan \\ ${ }^{2}$ Department of Legal Medicine, School of Medicine, Tokyo Women's Medical University, 8-1 Kawada-cho, Shinjuku, \\ Tokyo 162-8666, Japan \\ ${ }^{3}$ University of Toronto and University Health Network, Toronto, ON, Canada M5G1L7 \\ ${ }^{4}$ Nihon Pharmaceutical University, 10281 Inacho-komuro, Kita-adachi-gun, Saitama-ken, Saitama 362-0806, Japan \\ Correspondence should be addressed to Nanako Kawaguchi; nanako.res@gmail.com
}

Received 30 April 2013; Accepted 8 July 2013

Academic Editor: Jan A. Miernyk

Copyright (C) 2013 Nanako Kawaguchi et al. This is an open access article distributed under the Creative Commons Attribution License, which permits unrestricted use, distribution, and reproduction in any medium, provided the original work is properly cited.

\begin{abstract}
Stem cells (embryonic stem cells, somatic stem cells such as neural stem cells, and cardiac stem cells) and cancer cells are known to aggregate and form spheroid structures. This behavior is common in undifferentiated cells and may be necessary for adapting to certain conditions such as low-oxygen levels or to maintain undifferentiated status in microenvironments including stem cell niches. In order to decipher the meaning of this spheroid structure, we established a cardiosphere clone (CSC-21E) derived from the rat heart which can switch its morphology between spheroid and nonspheroid. Two forms, floating cardiospheres and dish-attached flat cells, could be switched reversibly by changing the cell culture condition. We performed differential proteome analysis studies and obtained protein profiles distinct between spherical forms and flat cells. From protein profiling analysis, we found upregulation of glycolytic enzymes in spheroids with some stress proteins switched in expression levels between these two forms. Evidence has been accumulating that certain chaperone/stress proteins are upregulated in concert with cellular changes including proliferation and differentiation. We would like to discuss the possible mechanism of how these aggregates affect cell differentiation and/or other cellular functions.
\end{abstract}

\section{Introduction}

Two epoch accomplishments in the first decade of 21st century are changing the scope of biomedical research. The first was the completion of the human genome project [1], which enabled the onset of "Omics" or the integrative approach (System Biology) [2]. The second was the discovery of adult stem cells in human [3] followed by induction of pluripotency by Yamanaka factors (Oct3/4, Sox, Klf4, and c-Myc) in both mouse and human somatic cells $[4,5]$. Adult stem cells are undifferentiated cells found throughout the body after development. They have the ability to self-renew indefinitely and have the developmental potential to generate many other cell types due to cell fate switching induced by extracellular environmental signals [3]. Plasticity of stem cells as well as the induction and reprogramming of somatic cells ignited the hope of discovering cellular therapy for the regeneration of damaged body parts. The revelation of the involvement of extracellular factors in switching cell types resulted in paradigm shift from "genetic determinism", the paradigm that all biological processes follow the one-way instruction stored in genomes to an "environment-genome interaction" understanding.

Studies on the regulatory molecular mechanisms underlying these changes often rely on gene expression analyses with transcription profiling (transcriptome) and microarrays. These mRNA analyses, however, have limitations because of variability in mRNA stability, the translational rates of 
genes, and protein degradation. Indeed, several investigations revealed that some of the protein expression levels are poorly correlated with the respective mRNA levels $[6,7]$. On the other hand, proteome analysis can cover a wide range of expressed proteins including unknown products and also has the potential to provide information on posttranslational modification and subcellular localization of proteins. Recent reviews of proteome analyses of embryonic stem cells show that some proteins can be used as common indicators of "stemness" [8-10]. Although proteome profiling requires more technical refinements to be readily applicable for general integrative research, the results obtained are already becoming uniquely valuable in gaining insights into a variety of the developmental processes.

The adult mammalian heart has been traditionally regarded as a terminally differentiated organ. Recent evidence, however, indicates that it has resident stem cells with self-renewing capacity. From rodent and human adult hearts, cells expressing c-kit, Sca-1, and MDR1 antigens were isolated, and they were demonstrated to be clonogenic and multipotent, with the capacity of generating cardiac myocytes, smooth muscle, and endothelial cells [11, 12]. These results indicate that cardiac stem cells reside in the heart, maintain their stem cell properties, and are capable of responding to stimuli to generate cells for repairing damaged tissue, such as in the case of heart failure or myocardial infarction [1214]. We also isolated cardiac stem cells from the rat heart and found that they are responsive to environmental factors and are plastic cells with multilineage potential [15-19]. Out of bulk culture of these cardiac stem cells, we isolated a unique cardiosphere clone which changes its shape from round spherical cells in aggregates to flat, adherent cells [20]. The shape change was a reversible process manipulated by switching the culture condition. The comparative proteome analysis of the two cell shapes showed dramatic alteration in protein profiles, especially of metabolic alteration and the switches in the expression of chaperons members. Apart from growth factors and nutrients, we would like to address the possibility of mechanical stress applied to the cell surface as being a trigger in cell fate determination [21-25]. The concept that different extracellular environments command the intracellular activity needs to be extensively explored for manipulating stem cells for regenerative therapy.

\section{Isolation of Cardiac Stem Cells from the Heart}

In 2002, Hierlihy et al. reported that the adult mouse myocardium retains an endogenous stem cell-like population that is activated during growth challenge [26]. In 2003, Oh et al. isolated stem cell antigen-1-positive $\left(\mathrm{Sca}^{+}{ }^{+}\right)$cells from the adult mouse myocardium, which migrate to the injured myocardium when administered intravenously after ischemia/reperfusion [27]. Beltrami et al. reported the presence of cardiac resident stem cells by isolating c-kit ${ }^{\text {pos }}$ cells from adult rat hearts by using immunomagnetic beads and FACS sorting [12]. These cardiac c-kit ${ }^{\text {pos }}$ cells are described as self-renewing clonogenic multipotent cells that give rise to myocytes, smooth muscle cells, and endothelial cells. Messina et al. were the first to isolate similar clonogenic cardiac stem cells from human biopsy tissues [11]. Matsuura et al. used an immunopurification system to isolate $\mathrm{Sca}-1^{+}$cells from the adult murine heart, which differentiated into beating cardiomyocytes after induction of differentiation by oxytocin. Sca- $1^{+}$ cells were also induced to differentiate into cells with osteocyte or adipocyte characteristics indicating their multipotency [28]. Linke et al. used dog hearts and immunopurification and isolated c-kit ${ }^{\mathrm{pos}}, \mathrm{MDR}^{+}$, and Sca- $1^{+}$cells that were self-renewing, clonogenic, and multipotent [29]. These results suggest that there are multiple types of cardiac adult stem cells.

In their study, Linke et al. minced tissues and cultured explants for 1-3 weeks. A layer of fibroblast-like cells was generated from the adherent explants, over which small phase-bright cells migrated and clustered together forming spheroids or cardiospheres (CSs) [29]. These CSs were periodically harvested by treatment with EDTA-trypsin and allowed to grow on poly-D-lysine-coated culture surfaces in specific culture media. The explant CSs were also obtained from murine hearts. Both human and murine explant CSs were self-renewing and clonogenic and reported to produce spontaneously beating cells [11]. Some of the cloned cells generated self-adherent cell aggregates or spheroids. Cardiospheres have been used for isolation of cardiomyocyte progenitor cells $[11,13]$. They are a heterogeneous cell population, and, in bulk, they express several stemness genes, such as ckit and MDR1, but also express cardiac-specific gene such as Nkx2.5 [30]. Because of their heterogeneity, some suggested that cardiomyocytes and/or cardiomyocyte progenitors were contaminants in these spheres and became beating cells when matured [31]. On the other hand, cardiospheres have been tried numerous times for the regeneration of the ischemic heart, and positive results have been reported [32-42]. Moreover, the human cardiospheres were applied to infarcted rodent hearts, and positive effects have been observed in terms of their expansion and differentiation resulting in thickening of tissue [34]. Makkar et al. reported that cardiosphere-derived cells were used for phase 1 clinical trials, and they warrant a phase 2 study [42]. Readers can refer to review articles for details about other types of cardiac stem cells $[21,22,43-48]$.

\section{Cardiospheres}

Spheroids have the morphology typically observed in the early developmental stages of various cell lineages such as embryonic stem cells (ESCs), neurospheres, embryoid bodies (EBs) observed in teratocarcinoma cultures, and induced pluripotent stem cells (iPSCs) $[4,5,49,50]$. Some tumor cells can be grown as multicellular spheroids [51]. Spheroids have a three-dimensional (3D) architecture, a core consisting of aggregated cells adhering to each other, and surface monolayer of cells surrounding the core cells. The core cells are likely to have less access to nutrients, oxygen, and growth factors because the surface monolayer of cells shields them from the environment and because they are tightly packed. In glioma spheroids, Khaitan et al. showed that average glucose 
consumption and lactate production are 2-3 times higher in viable spheroid cells compared to monolayer cells [52]. Since hypoxia inducible factor- $1 \alpha$ (HIF- $1 \alpha)$ is expressed only in spheroids, the increase in glycolysis is likely induced by hypoxia with reduced mitochondrial mass and activity. Tumor spheroids are resistant to drugs and radiation [53]. Because of this property, spheroids are likely to be more beneficial for the preservation of stem cells within these structures as hypoxic conditions mean less oxidative damage. The cell shapes inside the spheroids might also alter cellular properties, resulting in different mechanosensitivities and responses to stimuli. Armstrong et al. [54] cultured fetal chick myocardium and demonstrated that reaggregated cardiomyocytes from tissue spheroids were responsive to several growth factors whereas the cardiomyocytes maintained in monolayered, flattened cells lost this responsiveness, thus indicating that cell shape altered the internal property of cardiomyocytes [54].

For human studies, explant cardiosphere-derived cells (CDCs) are favored because of the advantage of being able to isolate cells from very small fragments of biopsy specimens of human myocardium. In vitro, these cells multiply many times without losing their differentiation potential. However, explant CDCs are a complex mixture of heterogeneous

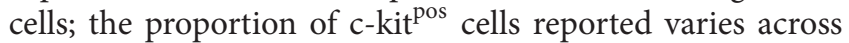
different studies [13, 55]. Several research groups injected human explant CDCs into infarcted rodents and produced chimeric hearts with functional improvements [13, 30, 34, 55]. Johnston et al. also injected pig explant CDCs into infarcted pigs, resulting in injury improvement [33]. On the other hand, Shenje et al. reported that murine explant CDCs transplanted into mice with peri-infarcts produce chimeras without cardiomyocyte differentiation [56]. Andersen et al. prepared explant CDCs from neonatal rats and mice; however, these lacked cardiomyogenic potential on filtration [31]. Therefore, the mechanism by which the injected cells repair infarct damages remains controversial with the argument being between the following possibilities: (1) the injected cells stimulate the release of factors to help heal the damage; (2) they fuse with the host's ailing heart cells to replenish and compensate for the damaged mitochondria; or (3) the injected stem cells transform into heart muscle. Davis et al. point out that since the primary explants are a complex mixture of cells, subtle variations in the culture technique and conditions might alter the outcome [30]. Davis et al. later refined the technique by trying to limit phenotype drift during cell culture [35]. In this respect, Tang et al. isolated c-kit ${ }^{\text {pos }}$ cells from explant CDCs and preconditioned the cells prior to injection into animals with surgically induced myocardial damage [57]. They reported that hypoxic pretreatment of the cells results in a significant improvement in the recruitment of the injected cell to the ischemic myocardium.

\section{Characteristics of Immunopurified c-Kit ${ }^{\text {pos }}$ Cardiac Stem Cells (CSCs)}

Since the first report by Beltrami et al. [12], immunopurified $\mathrm{c}^{-\mathrm{kit}^{\mathrm{pos}}}$ cardiac stem cells (CSCs) have been investigated for their self-renewing, clonogenic, and multipotent properties [15-20, 58-64]. c-Kit, also called KIT or CD117, is a cytokine receptor that binds to stem cell factor (SCF, also known as "steel factor" or "c-kit ligand") [65]. c-Kit and its ligand (SCF) are known to be essential for hematopoiesis, melanogenesis, and fertility. Altered forms of this receptor may be associated with some types of cancer. Using transgenic mice with green fluorescent protein (GFP) under the transcriptional control of the c-kit locus, Tallini et al. recently observed c-kit ${ }^{\text {pos }}$ cells inside embryonic and postnatal developing hearts [66]; however, they decline rapidly in the initial weeks after birth [54]. These observations prove that $\mathrm{c}-\mathrm{kit}^{\mathrm{pos}}$ cells are involved at least in neonatal stages of cardiomyogenesis in vivo. Also, by damaging heart tissue in adult mice, c-kit ${ }^{\text {pos }}$ cells were observed transiently [54]. In human biopsies, $80 \%$ of cardiosphere-derived stem cells from the myocardial infarcted patients were c-kit and MDR-1 double positive [64]. The role of c-kit may change according to its expression level [22].

We studied the "stemness" and the cardiogenic potential of immunopurified c-kit ${ }^{\text {pos }}$ CSCs by splitting the purified cells in fractions and culturing them in bulk in vitro for over 40 passages. The long-term bulk culture lots were followed by mRNA marker analysis for "stemness" (Oct-4, Nanog, Klf-4, and Sox), cardiomyocyte lineage (GATA-4, MLC2v, cardiac actin, desmin, and connexin 43 ), adipocyte lineage ( $\alpha$ PPAR), smooth muscle cells (smooth muscle actin), and skeletal muscle lineage (myogenin and desmin) gene expression. In the c-kit ${ }^{\text {pos }}$ CSCs bulk cultures from whole rat hearts, "stemness" and cardiac markers expressed at the onset of culture were lost in about half of the bulk cultures after 40 passages with more than half starting to express markers of differentiated cells [15], some even with double-lineage markers. This indicates

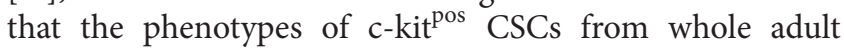
hearts drift more toward differentiated cells during long-term culture [15]. The amount of GATA- 4 mRNA expression drifts at different passages of the bulk culture lots [15]. However, when the source of $\mathrm{c}-\mathrm{kit}^{\mathrm{pos}} \mathrm{CSC}$ is limited to the left atrium, a higher proportion of bulk cultures exhibited markers for cardiac lineage and some produced beating cells when placed into differentiation media with cytokines Il-3 and SCF [18]. The bulk cultures were subjected to cloning by limited dilution methods, and the characteristics of clones obtained were not perfectly identical to the original bulk culture, perhaps due to heterogeneity within the bulk culture cells $[15,17,18]$. Nevertheless, the clones exhibit similar expression patterns as bulk cultures overall.

Among the bulk cultures, CSC-BC21 showed the greatest amount of spherical aggregate formation. A clone CSC-21E was derived from this bulk culture by limited dilution and maintained similar frequencies of spherical aggregate formation as the original bulk culture $[15,20]$. CSC-21E cells showed two distinct morphologies, floating cardiospheres (flCS) composed of round cells and dish-attached cardiospheres ( $\mathrm{daCS}$ ) composed of flattened fibroblastic cells. These two different morphologies were obtained by switching plastic dishes; namely, flCS were obtained when cultured on bacterial dishes and daCS were obtained when transferred to cell culture dishes. The bacterial dishes were molded with virgin polystyrene to give a hydrophobic surface while the cell 
culture dishes were modified by plasma discharge to give a charged polystyrene surface. Trypsin treatment of daCS and transfer to bacterial dishes result in cells reverting to flCS, and this ability remained for at least 3 days after flCS were converted to daCS. Since this morphological change does not require any feeder cells or additional growth factors, clone CSC-21E appeared to be an attractive model for studying the effect of cell shape in determining cell properties.

\section{Proteomic Comparison of Floating (flCS) and Attached (daCS) Cells of Clone CSC-21E}

The two-dimensional (2D) fluorescence difference gel electrophoresis (DIGE) system uses two samples labeled separately with different fluorescent labels and is subjected to a $2 \mathrm{D}$ polyacrylamide gel electrophoresis after combining the two samples. The system can show overall protein profiles common to both samples and also is sensitive in detecting proteins that have different expression levels in the two samples. The clone CSC-21E was subjected to 2D DIGE to study the difference between protein expression levels in flCS and daCS.

Overall protein profiles exhibited many "stemness" indicators observed in ESCs such as high levels of glycolytic and metabolic enzymes, a variety of chaperones or stress proteins, and annexins in both shapes [8-10, 20]. However, some "stemness" indicators including peroxiredoxin 1, T-complex protein 1, and translationally controlled tumor proteins were absent, suggesting that cardiospheres exist as an intermediately differentiated state with partial stem cell-like characteristics. Stress proteins are highly expressed in both flCS and daCS. Stress proteins are involved in regulating protein folding in various cell compartments and intracellular trafficking [67]. Some stress proteins are also implicated in the "stemness" of pluripotent cells as well as in the regulation of cell proliferation and differentiation [68-70].

We also detected proteins which change expression levels in response to the shape change from floating aggregates to dish-attached expanded cells; see Figure 1. Metabolic enzymes such as glycolytic enzymes comprised about half of the proteins whose expression decreased upon cell attachment. In flCS cells, oxygen supply is limited by aggregation, which minimizes exposure to the environment. Levels of glutathione-S-transferase, pentose phosphate pathway enzymes, transaldolase, and a transaldolase isoform were higher in flCS than daCS. Furthermore, decrease in the levels of these proteins suggests that flCS can avoid oxidative stress better than daCS $[7,71]$. In general, the defense system for oxidative stress is better in stem cells than differentiated cells $[69,70]$. Therefore, since flCS have a superior antioxidative capacity compared to daCS, this also indicates that flCS cells maintain more "stemness" properties than daCS cells.

There are 2 other observations from the present CSC investigation that are worth noting. The first is the proteomic observation of a switch in chaperons that occurs when floating cardiosphere cells become dish-attached cells. Among stress proteins, Hsp90, chaperonin 60, and calreticulin exhibit increased expression in attached cells. Hsp90 is known to participate in the stabilization and refolding of denatured proteins after stress and also plays a key role in the maturation of signal transduction proteins and assembly of myofibril filaments [72, 73]. Calreticulin is the most notable among the stress proteins upregulated upon cell attachment, because it is known to be essential for cardiac development [74]. The increase in calreticulin expression induces increase in the levels of both vinculin and N-cadherin, which play an important role in increasing cell adhesiveness to their substratum and communication with their neighboring cells. The upregulation of Hsp90 and calreticulin after the transition from flCS to daCS clearly indicates that this is a key step toward forming cardiomyocytes.

Notably, we found high levels of annexin family proteins in CS cells. Annexins are a family of membrane-binding proteins, and they bind to phospholipid surfaces in a $\mathrm{Ca}^{++}$dependent manner. Annexins A1, A2, and A6 are also actinbinding proteins [75]. We observed high expression levels of annexins A1 and A2 and distinct expression of annexins A4 and A5 in both flCS and daCS. On the other hand, annexin A7 expressed in flCS cells was decreased in daCS while the expression of annexin A6 was increased in daCS. The change from annexin A7 to A6 concomitant with flCS/daCS switching might suggest a different requirement for the cytoskeletal organization and formation of the plasma membrane in these cells. Molecular chaperones help many signaling molecules maintain their activation-competent states and regulate various signaling processes [76]. Further investigation in this area may aid the development of chaperone-modulating chemicals and drugs that might maintain the "stemness" or manipulate the differentiation of certain cells.

The second is the control of cell fate by physical interactions with the substrate surface. Guilak et al. elegantly reviewed the role of the substrate extracellular matrix (ECM) in inducing changes in cell shape [77]. Interestingly, the artificial alteration of physical structure of ECM resulted in cell shape from rounded to flattened morphology and consequently influenced cell fate. Cell adhesion to ECM results in activation of Rho, a member of the Ras superfamily of small GTP-binding proteins, which is involved in signaling a switch between adipogenesis and myogenesis [78, 79]. The switch between floating and adherent cells alters not only the morphology of the cell, but also the expression of functional proteins. Since the present experimental system does not involve ECM for cell adhesion, it may be instrumental for exploring how mechanosensitive components of the cell surface trigger molecules that determine cell fate.

\section{Stem Cell Niche and Cardiospheres}

In 1978, Schofield proposed the "niche" hypothesis to describe the physiologically limited microenvironment that supports stem cells [80]. Since then, stem cells are thought to exist in specialized microenvironments known as niches, which play an important role in microenvironment-stem cell interactions [81]. Stem cell niches are often located in regions of low oxygen supply [82] and require elevated glycolysis. Kondoh et al. reported that the proliferative capacity of murine ES cells correlates with high glycolytic enzyme activity and low oxygen consumption [83]. Unwin and Whetton identified several 

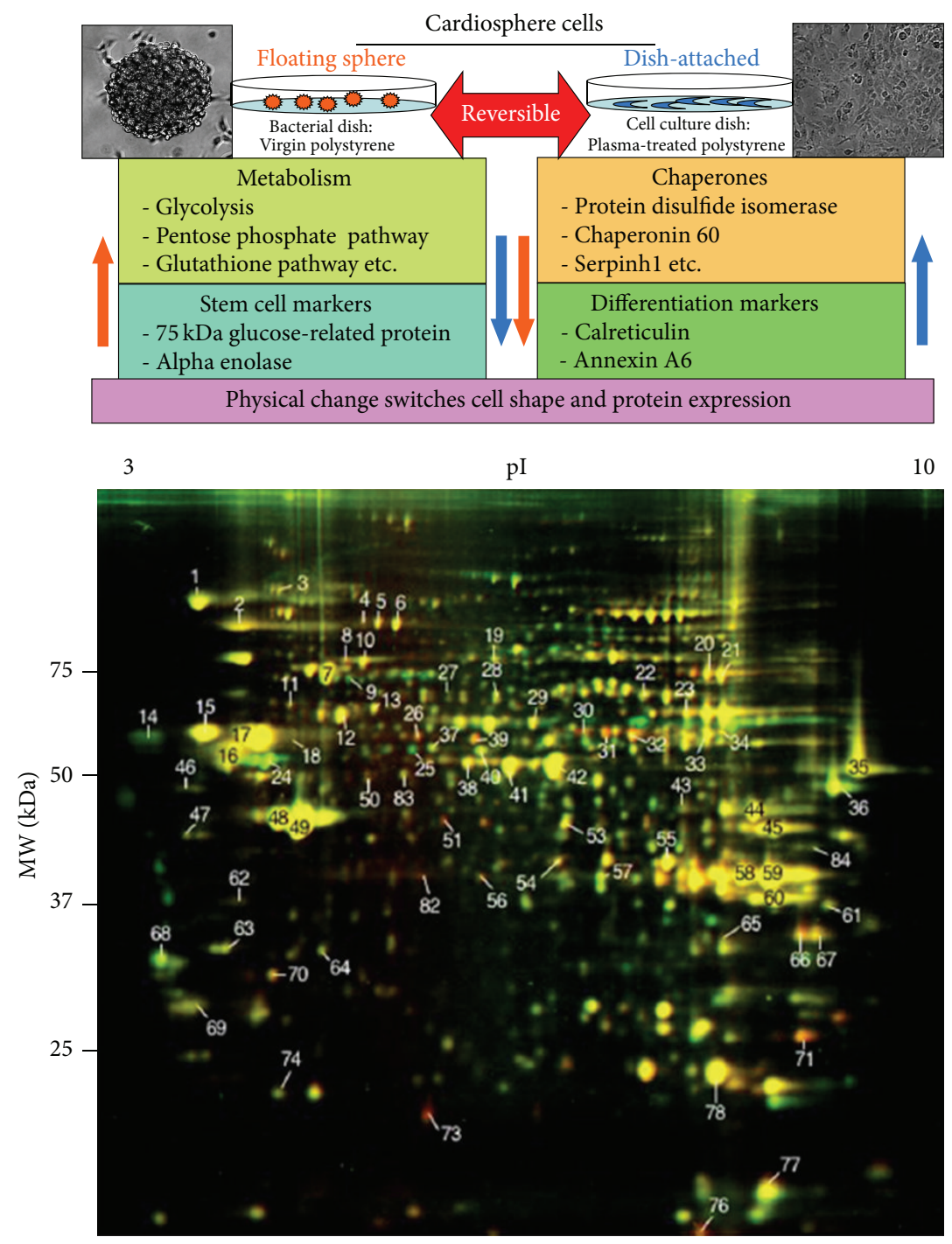

FIGURE 1: Upper Panel: Category of proteins differentially expressed in floating cardiosphere (flCS) cells and dish-attached cardiosphere (daCS) cells reported in Machida et al. [20]. Among the proteins successfully identified, about $44 \%$ were differentially expressed. Lower Panel: Comparative 2D-DIGE of CSC-21E whole cell lysates from flCS (red) and daCS (green) cultures. Proteins with similar amounts in flCS and daCS appear as yellow spots, whereas proteins differentially expressed show reddish (more abundant in flCS) or greenish (more abundant in daCS) spots. The figure was modified from Figure 3 of Machida et al. [20] with permission.

components of anaerobic glycolysis that exhibit decreased expression upon the loss of stem cell characteristics [7].

A primary function of the niche is to anchor stem cells to the microenvironment suitable in maintaining their healthy progenitor properties. To stabilize stem cell characteristics during long-term culture, it is critical to understand the nature and stimulation of the stem cell niche. The proteomic profile of floating CSs indicates that cardiospheres are adapted for hypoxia. The low oxygen pressure in stem cell niches was recently identified $[84,85]$. Although we inhale an ambient oxygen tension of $21 \%(160 \mathrm{mmHg})$, the partial pressure of oxygen $\left(\mathrm{pO}_{2}\right)$ in organs and tissues inside our body drops to 2-9\% (14-65 mmHg), which is considered normal for cells $[86,87]$. Consequently, in the routine laboratoryscale cell culture, the ambient $\mathrm{pO}_{2}$ of $21 \%$ is too high for cells, and the benefits of adjusting to their physiological
$\mathrm{pO}_{2}$ are obvious and require serious consideration. Toussaint et al. have cited many examples of the physiological $\mathrm{pO}_{2}$ level of $2-9 \%$ providing benefits to the maintenance of a variety of cells [85]. Slightly lower oxygen tensions are indicated for several stem cell niches $[84,85]$. Low $\mathrm{O}_{2}$ tension prevents spontaneous differentiation of human embryonic stem cells [88] and is required to activate HIF, which is a master gene regulator that controls several dozen genes in response to hypoxia $[89,90]$.

\section{Proteomic Comparison Studies in Spheroids}

Spheroid-like structures were formed in various stem cells and cancer stem cells such as neurospheres, dental follicle precursor cells, and cancer cells [91-94]. Proteomic comparisons were performed between monolayer and tumor 
spheroids, and it was suggested that cell-stress proteins, such as HSP-90, 70, and 60 were upregulated in spheres [92, 93]. Moreover, in prostate cancer stem cells (DU145), CD $44^{+}$ spherical forms maintained stemness, suggesting that the spheroid state may be advantageous for the maintenance of stem cells [94]. The metastatic activity of these cells is regulated by the TGF-beta signaling pathway [93]. Furthermore, the studies using EBs suggest that heat shock proteins (HSPA5 and HSPA8) are upregulated in undifferentiated states, suggesting that alteration of expression levels of stress proteins is associated with changes by differentiation stages [95].

\section{Conclusion}

Proteomic analysis of various spheroid-like cell aggregates reveals that they have distinct protein profiles common among them, that is, upregulation of certain metabolic enzymes adaptable to low oxygen condition and the expression level of some stress proteins when compared with monolayer cultures. Next questions are to unravel the relationship between the factors involved in cell shape, surface mechanosensitivity, and oxygen pressure and between the alteration in protein profiles. Understanding the regulation in protein profile changes is an area expected to provide further insights. Thus technology to manipulate the protein profile may lead to the development of regenerative therapy.

\section{References}

[1] F. S. Collins, E. S. Lander, J. Rogers, and R. H. Waterson, "Finishing the euchromatic sequence of the human genome," Nature, vol. 431, no. 7011, pp. 931-945, 2004.

[2] H. Kitano, "Systems biology: a brief overview," Science, vol. 295, no. 5560, pp. 1662-1664, 2002.

[3] M. Raff, "Adult stem cell plasticity: fact or artifact?" Annual Review of Cell and Developmental Biology, vol. 19, pp. 1-22, 2003.

[4] K. Takahashi and S. Yamanaka, "Induction of Pluripotent Stem Cells from Mouse Embryonic and Adult Fibroblast Cultures by Defined Factors," Cell, vol. 126, no. 4, pp. 663-676, 2006.

[5] K. Takahashi, K. Tanabe, M. Ohnuki et al., "Induction of Pluripotent Stem Cells from Adult Human Fibroblasts by Defined Factors," Cell, vol. 131, no. 5, pp. 861-872, 2007.

[6] S. P. Gygi, Y. Rochon, B. R. Franza, and R. Aebersold, "Correlation between protein and mRNA abundance in yeast," Molecular and Cellular Biology, vol. 19, no. 3, pp. 1720-1730, 1999.

[7] R. D. Unwin and A. D. Whetton, "Systematic proteome and transcriptome analysis of stem cell populations," Cell Cycle, vol. 5, no. 15, pp. 1587-1591, 2006.

[8] H. Baharvand, A. Fathi, D. van Hoof, and G. H. Salekdeh, "Concise review: trends in stem cell proteomics," Stem Cells, vol. 25, no. 8, pp. 1888-1903, 2007.

[9] L. Ma, B. Sun, L. Hood, and Q. Tian, "Molecular profiling of stem cells," Clinica Chimica Acta, vol. 378, no. 1-2, pp. 24-32, 2007.

[10] D. van Hoof, R. Passier, D. Ward-van Oostwaard et al., "A quest for human and mouse embryonic stem cell-specific proteins," Molecular and Cellular Proteomics, vol. 5, no. 7, pp. 1261-1273, 2006.
[11] E. Messina, L. de Angelis, G. Frati et al., "Isolation and expansion of adult cardiac stem cells from human and murine heart," Circulation Research, vol. 95, no. 9, pp. 911-921, 2004.

[12] A. P. Beltrami, L. Barlucchi, D. Torella et al., "Adult cardiac stem cells are multipotent and support myocardial regeneration," Cell, vol. 114, no. 6, pp. 763-776, 2003.

[13] R. R. Smith, L. Barile, H. C. Cho et al., "Regenerative potential of cardiosphere-derived cells expanded from percutaneous endomyocardial biopsy specimens," Circulation, vol. 115, no. 7, pp. 896-908, 2007.

[14] L. Barile, E. Messina, A. Giacomello, and E. Marbán, "Endogenous Cardiac Stem Cells," Progress in Cardiovascular Diseases, vol. 50, no. 1, pp. 31-48, 2007.

[15] S. Miyamoto, N. Kawaguchi, G. M. Ellison, R. Matsuoka, T. Shin'Oka, and H. Kurosawa, "Characterization of long-term cultured c-kit+ cardiac stem cells derived from adult rat hearts," Stem Cells and Development, vol. 19, no. 1, pp. 105-116, 2010.

[16] N. Kawaguchi, A. J. Smith, C. D. Waring et al., "c-kit ${ }^{\text {pos }}$ GATA-4 high rat cardiac stem cells foster adult cardiomyocyte survival through IGF-1 paracrine signalling," PLoS ONE, vol. 5, no. 12, Article ID e14297, 2010.

[17] N. Kawaguchi, R. Nakao, M. Yamaguchi, D. Ogawa, and R. Matsuoka, "TGF- $\beta$ superfamily regulates a switch that mediates differentiation either into adipocytes or myocytes in left atrium derived pluripotent cells (LA-PCS)," Biochemical and Biophysical Research Communications, vol. 396, no. 3, pp. 619-625, 2010.

[18] M. K. Hasan, Y. Komoike, S.-I. Tsunesumi et al., "Myogenic differentiation in atrium-derived adult cardiac pluripotent cells and the transcriptional regulation of GATA4 and myogenin on ANP promoter," Genes to Cells, vol. 15, no. 5, pp. 439-454, 2010.

[19] H. Hosseinkhani, M. Hosseinkhani, S. Hattori, R. Matsuoka, and N. Kawaguchi, "Micro and nano-scale in vitro 3D culture system for cardiac stem cells," Journal of Biomedical Materials Research A, vol. 94, no. 1, pp. 1-8, 2010.

[20] M. Machida, Y. Takagaki, R. Matsuoka, and N. Kawaguchi, "Proteomic comparison of spherical aggregates and adherent cells of cardiac stem cells," International Journal of Cardiology, vol. 153, no. 3, pp. 296-305, 2011.

[21] N. Kawaguchi, "Adult cardiac-derived stem cells: differentiation and survival regulators," Vitamins and Hormones, vol. 87, pp. $111-125,2011$

[22] N. Kawaguchi, "Stem cells for cardiac regeneration and possible roles of the transforming growth factor- $\beta$ superfamily," BioMolecular Concepts, vol. 3, no. 1, pp. 99-106, 2011.

[23] N. Kawaguchi, E. Hayama, Y. Furutani, and Y. Nakanishi, "Prospective in vitro models of channelopathies and cardiomyopathies," Stem Cells International, vol. 2012, Article ID 439219, 10 pages, 2012.

[24] N. Kawaguchi and Y. Nakanishi, "Cardiomyocyte regeneration," Cells, vol. 2, no. 1, pp. 67-82, 2013.

[25] Y. Takagaki, H. Yamagishi, and R. Matsuoka, "Factors Involved in Signal Transduction During Vertebrate Myogenesis," International Review of Cell and Molecular Biology, vol. 296, pp. 187272, 2012.

[26] A. M. Hierlihy, P. Seale, C. G. Lobe, M. A. Rudnicki, and L. A. Megeney, "The post-natal heart contains a myocardial stem cell population," FEBS Letters, vol. 530, no. 1-3, pp. 239-243, 2002.

[27] H. Oh, S. B. Bradfute, T. D. Gallardo et al., "Cardiac progenitor cells from adult myocardium: Homing, differentiation, and fusion after infarction," Proceedings of the National Academy of Sciences of the United States of America, vol. 100, no. 21, pp. 12313-12318, 2003. 
[28] K. Matsuura, T. Nagai, N. Nishigaki et al., "Adult Cardiac Sca-1-positive Cells Differentiate into Beating Cardiomyocytes," Journal of Biological Chemistry, vol. 279, no. 12, pp. 11384-11391, 2004.

[29] A. Linke, P. Müller, D. Nurzynska et al., "Stem cells in the dog heart are self-renewing, clonogenic, and multipotent and regenerate infarcted myocardium, improving cardiac function," Proceedings of the National Academy of Sciences of the United States of America, vol. 102, no. 25, pp. 8966-8971, 2005.

[30] D. R. Davis, Y. Zhang, R. R. Smith et al., "Validation of the cardiosphere method to culture cardiac progenitor cells from myocardial tissue," PLoS ONE, vol. 4, no. 9, Article ID e7195, 2009.

[31] D. C. Andersen, P. Andersen, M. Schneider, H. B. Jensen, and S. P. Sheikh, "Murine "cardiospheres" are not a source of stem cells with cardiomyogenic potential," Stem Cells, vol. 27, no. 7, pp. 1571-1581, 2009.

[32] D. R. Davis, E. Kizana, J. Terrovitis et al., "Isolation and expansion of functionally-competent cardiac progenitor cells directly from heart biopsies," Journal of Molecular and Cellular Cardiology, vol. 49, no. 2, pp. 312-321, 2010.

[33] P. V. Johnston, T. Sasano, K. Mills et al., "Engraftment, differentiation, and functional benefits of autologous cardiospherederived cells in porcine ischemic cardiomyopathy," Circulation, vol. 120, no. 12, pp. 1075-1083, 2009.

[34] I. Chimenti, R. R. Smith, T.-S. Li et al., "Relative roles of direct regeneration versus paracrine effects of human cardiospherederived cells transplanted into infarcted mice," Circulation Research, vol. 106, no. 5, pp. 971-980, 2010.

[35] K. Cheng, T.-S. Li, K. Malliaras, D. R. Davis, Y. Zhang, and E. Marbán, "Magnetic targeting enhances engraftment and functional benefit of iron-labeled cardiosphere-derived cells in myocardial infarction," Circulation Research, vol.106, no. 10, pp. 1570-1581, 2010.

[36] K. Malliaras, T.-S. Li, D. Luthringer et al., "Safety and efficacy of allogeneic cell therapy in infarcted rats transplanted with mismatched cardiosphere-derived cells," Circulation, vol. 125, no. 1, pp. 100-112, 2012.

[37] S.-T. Lee, A. J. White, S. Matsushita et al., "Intramyocardial injection of autologous cardiospheres or cardiosphere-derived cells preserves function and minimizes adverse ventricular remodeling in pigs with heart failure post-myocardial infarction," Journal of the American College of Cardiology, vol. 57, no. 4, pp. 455-465, 2011.

[38] A. J. White, R. R. Smith, S. Matsushita et al., "Intrinsic cardiac origin of human cardiosphere-derived cells," European Heart Journal, vol. 34, no. 1, pp. 68-75, 2013.

[39] R. Lautamäki, J. Terrovitis, M. Bonios et al., "Perfusion defect size predicts engraftment but not early retention of intramyocardially injected cardiosphere-derived cells after acute myocardial infarction," Basic Research in Cardiology, vol. 106, no. 6, pp. 1379-1386, 2011.

[40] C. A. Carr, D. J. Stuckey, J. J. Tan et al., "Cardiosphere-derived cells improve function in the infarcted rat heart for at least 16 weeks-an mri study," PLoS ONE, vol. 6, no. 10, Article ID e25669, 2011.

[41] J. Ye, A. Boyle, H. Shih et al., "Sca-1+ cardiosphere-derived cells are enriched for isll-expressing cardiac precursors and improve cardiac function after myocardial injury," PLOS ONE, vol. 7, no. 1, Article ID e30329, 2012.
[42] R. R. Makkar, R. R. Smith, K. Cheng et al., "Intracoronary cardiosphere-derived cells for heart regeneration after myocardial infarction (CADUCEUS): a prospective, randomised phase 1 trial," The Lancet, vol. 379, no. 9819, pp. 895-904, 2012.

[43] D. Torella, G. M. Ellison, B. Nadal-Ginard, and C. Indolfi, "Cardiac stem and progenitor cell biology for regenerative medicine," Trends in Cardiovascular Medicine, vol. 15, no. 6, pp. 229236, 2005.

[44] V. L. T. Ballard and J. M. Edelberg, "Stem cells and the regeneration of the aging cardiovascular system," Circulation Research, vol. 100, no. 8, pp. 1116-1127, 2007.

[45] M. Rubart and L. J. Field, "Stem cell differentiation: cardiac repair," Cells Tissues Organs, vol. 188, no. 1-2, pp. 202-211, 2008.

[46] R. R. Smith, L. Barile, E. Messina, and E. Marbán, "Stem cells in the heart: what's the buzz all about?-Part 1: preclinical considerations," Heart Rhythm, vol. 5, no. 5, pp. 749-757, 2008.

[47] H. Reinecke, E. Minami, W.-Z. Zhu, and M. A. Laflamme, "Cardiogenic differentiation and transdifferentiation of progenitor cells," Circulation Research, vol. 103, no. 10, pp. 1058-1071, 2008.

[48] D. Torella, C. Indolfi, D. F. Goldspink, and G. M. Ellison, "Cardiac stem cell-based myocardial regeneration: towards a translational approach," Cardiovascular and Hematological Agents in Medicinal Chemistry, vol. 6, no. 1, pp. 53-59, 2008.

[49] G. R. Martin and M. J. Evans, "Differentiation of clonal teratocarcinoma cells: formation of embryoid bodies in vitro," Proceedings of the National Academy of Sciences of the United States of America, vol. 72, no. 4, pp. 1441-1445, 1975.

[50] O. N. Suslov, V. G. Kukekov, T. N. Ignatova, and D. A. Steindler, "Neural stem cell heterogeneity demonstrated by molecular phenotyping of clonal neurospheres," Proceedings of the National Academy of Sciences of the United States of America, vol. 99, no. 22, pp. 14506-14511, 2002.

[51] R. Sutherland, "Spheroids in cancer research," Cancer Research, vol. 41, no. 7, pp. 2980-2984, 1981.

[52] D. Khaitan, S. Chandna, M. B. Arya, and B. S. Dwarakanath, "Establishment and characterization of multicellular spheroids from a human glioma cell line; implications for tumor therapy," Journal of Translational Medicine, vol. 4, article 12, 2006.

[53] G. Francia, S. Man, B. Teicher, L. Grasso, and R. S. Kerbel, "Gene expression analysis of tumor spheroids reveals a role for suppressed DNA mismatch repair in multicellular resistance to alkylating agents," Molecular and Cellular Biology, vol. 24, no. 15, pp. 6837-6849, 2004.

[54] M. T. Armstrong, D. Y. Lee, and P. B. Armstrong, "Regulation of proliferation of the fetal myocardium," Developmental Dynamics, vol. 219, no. 2, pp. 226-236, 2000.

[55] C. Bearzi, M. Rota, T. Hosoda et al., "Human cardiac stem cells," Proceedings of the National Academy of Sciences of the United States of America, vol. 104, no. 35, pp. 14068-14073, 2007.

[56] L. T. Shenje, L. J. Field, C. A. Pritchard et al., "Lineage tracing of cardiac explant derived cells," PLoS ONE, vol. 3, no. 4, Article ID e1929, 2008.

[57] Y. L. Tang, W. Zhu, M. Cheng et al., "Hypoxic preconditioning enhances the benefit of cardiac progenitor cell therapy for treatment of myocardial infarction by inducing CXCR4 expression," Circulation Research, vol. 104, no. 10, pp. 1209-1216, 2009.

[58] D. Torella, G. M. Ellison, S. Méndez-Ferrer, B. Ibanez, and B. Nadal-Ginard, "Resident human cardiac stem cells: role in cardiac cellular homeostasis and potential for myocardial regeneration," Nature Clinical Practice Cardiovascular Medicine, vol. 3, supplement 1, pp. S8-S13, 2006. 
[59] D. Torella, G. M. Ellison, I. Karakikes, and B. Nadal-Ginard, "Growth-factor-mediated cardiac stem cell activation in myocardial regeneration," Nature Clinical Practice Cardiovascular Medicine, vol. 4, supplement 1, pp. S46-S51, 2007.

[60] G. M. Ellison, D. Torella, I. Karakikes, and B. Nadal-Ginard, "Myocyte death and renewal: modern concepts of cardiac cellular homeostasis," Nature Clinical Practice Cardiovascular Medicine, vol. 4, supplement 1, pp. S52-S59, 2007.

[61] G. M. Ellison, D. Torella, I. Karakikes et al., "Acute $\beta$-adrenergic overload produces myocyte damage through calcium leakage from the ryanodine receptor 2 but spares cardiac stem cells," Journal of Biological Chemistry, vol. 282, no. 15, pp. 11397-11409, 2007.

[62] D. Torella, G. M. Ellison, I. Karakikes, and B. Nadal-Ginard, "Cardiovascular development: towards biomedical applicability-resident cardiac stem cells," Cellular and Molecular Life Sciences, vol. 64, no. 6, pp. 661-673, 2007.

[63] A. Leri, J. Kajstura, P. Anversa, and W. H. Frishman, "Myocardial regeneration and stem cell repair," Current Problems in Cardiology, vol. 33, no. 3, pp. 91-153, 2008.

[64] K. G. A. Rani, K. Jayakumar, G. Srinivas, R. R. Nair, and C. C. Kartha, "Isolation of ckit-positive cardiosphere-forming cells from human atrial biopsy," Asian Cardiovascular and Thoracic Annals, vol. 16, no. 1, pp. 50-56, 2008.

[65] J. Lennartsson and L. Rönnestrand, "Stem cell factor receptor/cKit: from basic science to clinical implications," Physiological Reviews, vol. 92, no. 4, pp. 1619-1649, 2012.

[66] Y. N. Tallini, S. G. Kai, M. Craven et al., "c-kit expression identifies cardiovascular precursors in the neonatal heart," Proceedings of the National Academy of Sciences of the United States of America, vol. 106, no. 6, pp. 1808-1813, 2009.

[67] J. C. Young, V. R. Agashe, K. Siegers, and F. U. Hartl, "Pathways of chaperone-mediated protein folding in the cytosol," Nature Reviews Molecular Cell Biology, vol. 5, no. 10, pp. 781-791, 2004.

[68] E. Prinsloo, M. M. Setati, V. M. Longshaw, and G. L. Blatch, "Chaperoning stem cells: a role for heat shock proteins in the modulation of stem cell self-renewal and differentiation?" BioEssays, vol. 31, no. 4, pp. 370-377, 2009.

[69] G. Saretzki, T. Walter, S. Atkinson et al., "Downregulation of multiple stress defense mechanisms during differentiation of human embryonic stem cells," Stem Cells, vol. 26, no. 2, pp. 455464, 2008.

[70] G. Saretzki, L. Armstrong, A. Leake, M. Lako, and T. Von Zglinicki, "Stress defense in murine embryonic stem cells is superior to that of various differentiated murine cells," Stem Cells, vol. 22, no. 6, pp. 962-971, 2004.

[71] F. Q. Schafer and G. R. Buettner, "Redox environment of the cell as viewed through the redox state of the glutathione disulfide/glutathione couple," Free Radical Biology and Medicine, vol. 30, no. 11, pp. 1191-1212, 2001.

[72] B. Chen, D. Zhong, and A. Monteiro, "Comparative genomics and evolution of the HSP90 family of genes across all kingdoms of organisms," BMC Genomics, vol. 7, article 156, 2006.

[73] J. D. Shao, H. Li, Y. Bian, and Y. Zhong, "Heat-shock protein $90 \alpha 1$ is required for organized myofibril assembly in skeletal muscles of zebrafish embryos," Proceedings of the National Academy of Sciences of the United States of America, vol. 105, no. 2, pp. 554-559, 2008.

[74] N. Mesaeli, K. Nakamura, E. Zvaritch et al., "Calreticulin is essential for cardiac development," Journal of Cell Biology, vol. 144, no. 5, pp. 857-868, 1999.
[75] S. E. Moss and R. O. Morgan, “The annexins," Genome Biology, vol. 5, no. 4, article 219, 2004.

[76] C. Soti, C. Pál, B. Papp, and P. Csermely, "Molecular chaperones as regulatory elements of cellular networks," Current Opinion in Cell Biology, vol. 17, no. 2, pp. 210-215, 2005.

[77] F. Guilak, D. M. Cohen, B. T. Estes, J. M. Gimble, W. Liedtke, and C. S. Chen, "Control of Stem Cell Fate by Physical Interactions with the Extracellular Matrix," Cell Stem Cell, vol. 5, no. 1, pp. 17-26, 2009.

[78] R. Sordella, W. Jiang, G.-C. Chen, M. Curto, and J. Settleman, "Modulation of Rho GTPase signaling regulates a switch between adipogenesis and myogenesis," Cell, vol. 113, no. 2, pp. 147-158, 2003.

[79] B. A. Bryan, D. C. Mitchell, L. Zhao et al., "Modulation of muscle regeneration, myogenesis, and adipogenesis by the Rho family guanine nucleotide exchange factor GEFT,' Molecular and Cellular Biology, vol. 25, no. 24, pp. 11089-11101, 2005.

[80] R. Schofield, "The relationship between the spleen colony-forming cell and the haemopoietic stem cell. A hypothesis," Blood Cells, vol. 4, no. 1-2, pp. 7-25, 1978.

[81] M. R. Alison and S. Islam, "Attributes of adult stem cells," Journal of Pathology, vol. 217, no. 2, pp. 144-160, 2009.

[82] S. M. Dellatore, A. S. Garcia, and W. M. Miller, "Mimicking stem cell niches to increase stem cell expansion," Current Opinion in Biotechnology, vol. 19, no. 5, pp. 534-540, 2008.

[83] H. Kondoh, M. E. Lleonart, Y. Nakashima et al., "A high glycolytic flux supports the proliferative potential of murine embryonic stem cells," Antioxidants and Redox Signaling, vol. 9, no. 3, pp. 293-299, 2007.

[84] A. Mohyeldin, T. Garzón-Muvdi, and A. Quiñones-Hinojosa, "Oxygen in stem cell biology: a critical component of the stem cell niche," Cell Stem Cell, vol. 7, no. 2, pp. 150-161, 2010.

[85] O. Toussaint, G. Weemaels, F. Debacq-Chainiaux, K. Scharffetter-Kochanek, and M. Wlaschek, "Artefactual effects of oxygen on cell culture models of cellular senescence and stem cell biology," Journal of Cellular Physiology, vol. 226, no. 2, pp. 315321, 2011.

[86] M. C. Brahimi-Horn and J. Pouysségur, "Oxygen, a source of life and stress," FEBS Letters, vol. 581, no. 19, pp. 3582-3591, 2007.

[87] M. C. Simon and B. Keith, "The role of oxygen availability in embryonic development and stem cell function," Nature Reviews Molecular Cell Biology, vol. 9, no. 4, pp. 285-296, 2008.

[88] T. Ezashi, P. Das, and R. M. Roberts, "Low $\mathrm{O}_{2}$ tensions and the prevention of differentiation of hES cells," Proceedings of the National Academy of Sciences of the United States of America, vol. 102, no. 13, pp. 4783-4788, 2005.

[89] R. K. Bruick, “Oxygen sensing in the hypoxic response pathway: regulation of the hypoxia-inducible transcription factor," Genes and Development, vol. 17, no. 21, pp. 2614-2623, 2003.

[90] R. H. Wenger, "Cellular adaptation to hypoxia: $\mathrm{O}_{2}$-sensing protein hydroxylases, hypoxia-inducible transcription factors, and $\mathrm{O}_{2}$-regulated gene expression," FASEB Journal, vol. 16, no. 10, pp. 1151-1162, 2002.

[91] H. C. Beck, J. Petersen, O. Felthaus, G. Schmalz, and C. Morsczeck, "Comparison of neurosphere-like cell clusters derived from dental follicle precursor cells and retinal Müller cells," Neurochemical Research, vol. 36, no. 11, pp. 2002-2007, 2011.

[92] H. R. Kumar, X. Zhong, D. J. Hoelz et al., "Three-dimensional neuroblastoma cell culture: proteomic analysis between monolayer and multicellular tumor spheroids," Pediatric Surgery International, vol. 24, no. 11, pp. 1229-1234, 2008. 
[93] L. Gaedtke, L. Thoenes, C. Culmsee, B. Mayer, and E. Wagner, "Proteomic analysis reveals differences in protein expression in spheroid versus monolayer cultures of low-passage colon carcinoma cells," Journal of Proteome Research, vol. 6, no. 11, pp. 4111-4118, 2007.

[94] E.-K. Lee, H. Cho, and C.-W. Kim, "Proteomic analysis of cancer stem cells in human prostate cancer cells," Biochemical and Biophysical Research Communications, vol. 412, no. 2, pp. 279-285, 2011.

[95] A. Fathi, M. Pakzad, A. Taei et al., "Comparative proteome and transcriptome analyses of embryonic stem cells during embryoid body-based differentiation," Proteomics, vol. 9, no. 21, pp. 4859-4870, 2009. 

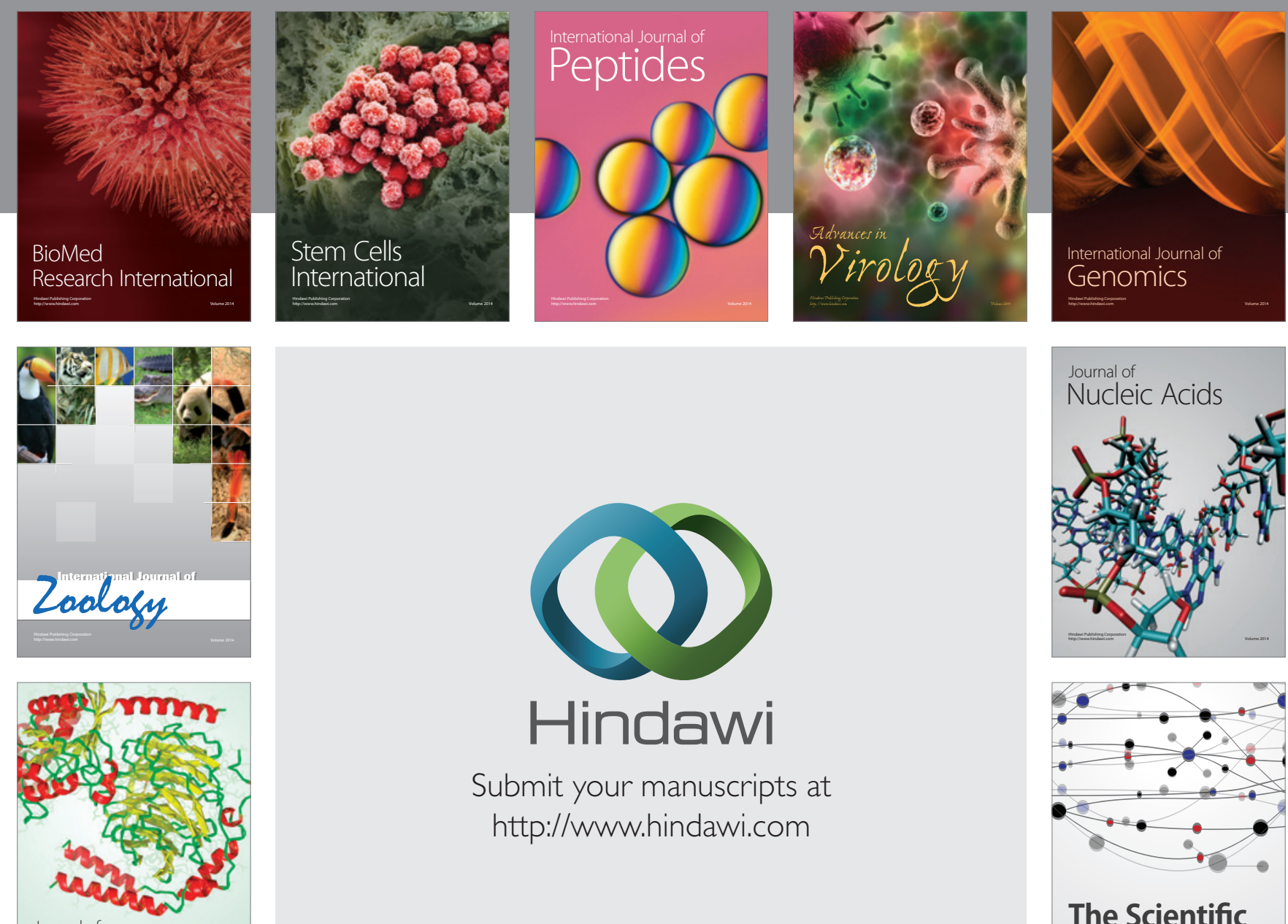

Submit your manuscripts at

http://www.hindawi.com

Journal of
Signal Transduction
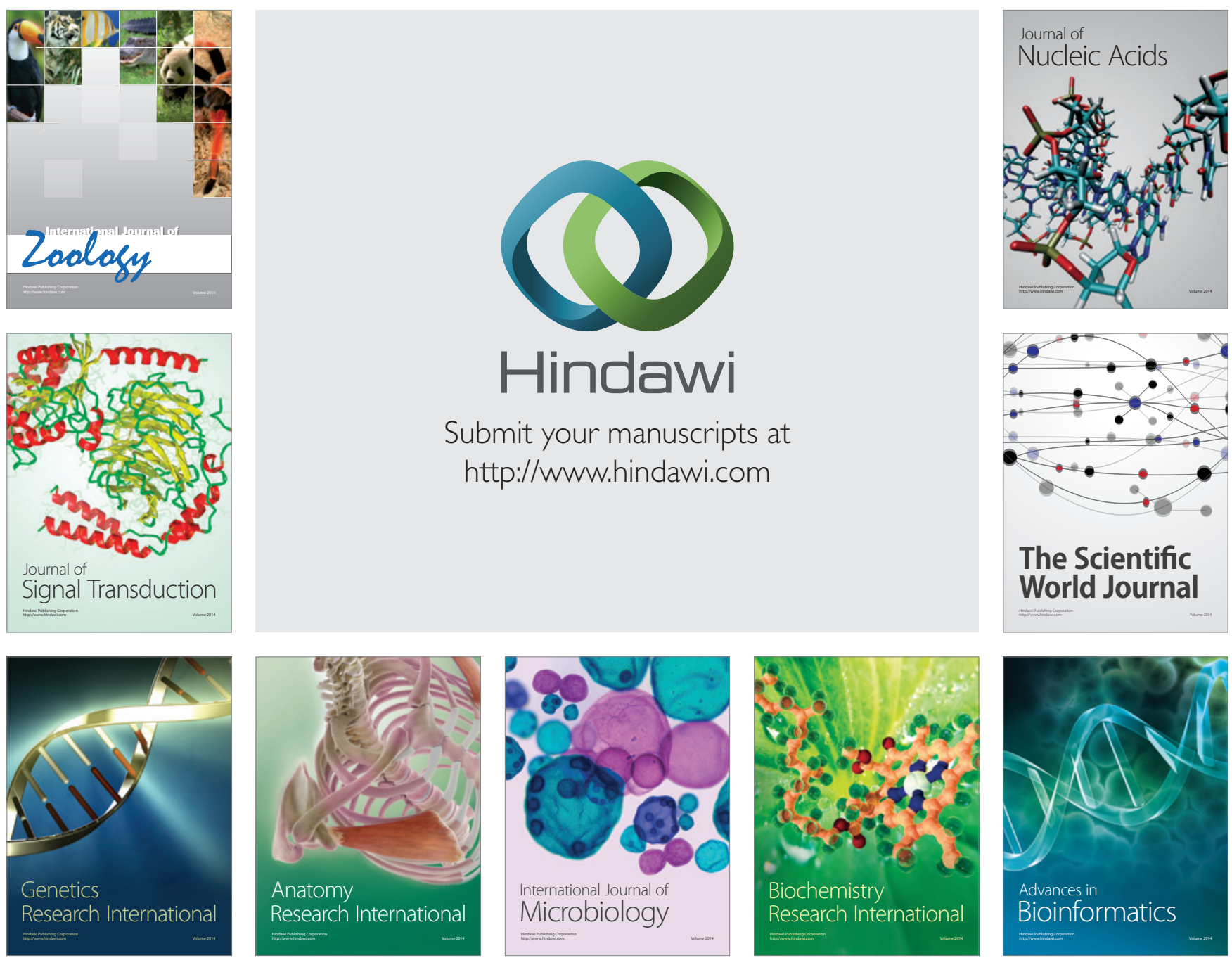

The Scientific World Journal
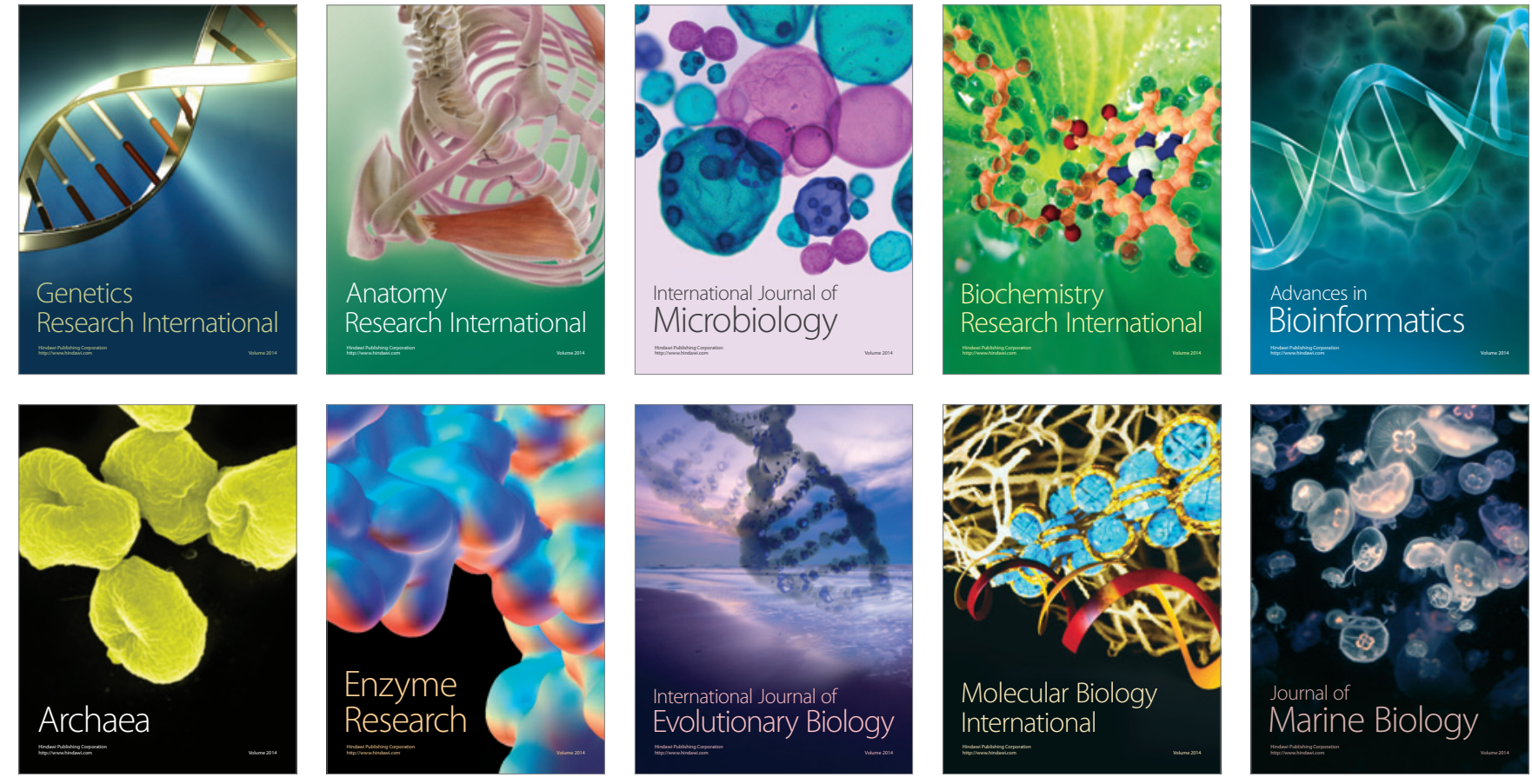